\title{
Measurement report: Immediate impact of the Taal volcanic eruption on atmospheric temperature observed from COSMIC-2 RO measurements
}

Saginela RavindraBabu and Yuei-An Liou

Center for Space and Remote Sensing Research, National Central University, Taiwan

* Correspondence: yueian@csrsr.ncu.edu.tw; Tel.: +886-3-4227151 (ext. 57631)

\section{Abstract}

For the first time after 43 years of its previous eruption in 1977, the Taal volcano in the Philippines $\left(14^{\circ} \mathrm{N}, 120^{\circ} .59 \mathrm{E}\right)$ erupted in the afternoon of 12 January, 2020. Interestingly, the Taal volcanic eruption was associated with a strong anticyclonic circulation at the upper levels over the western Pacific region in the northern hemisphere. As a result, the volcanic plumes were carried through the background upper level strong winds to the anticyclone over the Pacific Ocean within a few days following the eruption. In this study, the detailed vertical structure and the day-to-day temperature variability in response to the eruption is delineated by using highresolution temperature measurements from the recently launched Constellation Observing System for Meteorology, Ionosphere, and Climate (COSMIC)-2 radio occultation (RO) data. We describe the vertical temperature structure near (within 2 degree radius) and away ( $~ 5$ degree radius) from the volcano during its intense eruption day (13 January 2020). A significant temperature inversion at $\sim 15 \mathrm{~km}$ altitude is observed in the nearest temperature profiles (within 2 degree radius). Multiple tropopauses are evident in the temperature profiles that are available away from the volcano ( 5 degree radius). The cloud top altitude of $15.2 \mathrm{~km}$ detected from the $\mathrm{RO}$ bending angle anomaly method is demonstrated. Furthermore, the diurnal temperature and relative humidity anomalies are estimated over $\pm 5^{\circ}$ latitude and longitude radius from the volcano center and over the region of 10-20N, 160-180E with respect to the mean temperature of one week before the eruption. A persistent warming layer is 
29 observed at 16-19 km altitude range in both regions for several days after the eruption.

30 A strong increase of $\sim 50 \%$ relative humidity at $15 \mathrm{~km}$ altitude is also noticed just after

31 the eruption in the Taal volcano region. The present work shows the advantages and usefulness of the newly-launched COSMIC-2 data for near real-time temperature monitoring at shorter time scales with sufficient data.

Keywords: Taal volcanic eruption; COSMIC-2; temperature; relative humidity 5

\section{Introduction}

The volcanic eruptions are dominant natural sources of the stratospheric sulfate aerosols and have a strong impact on global climate (Robock, 2000, 2015). Over decades, the impact of volcanic sulfate aerosols on climate has received immense interest due to their strong cooling effect on the Earth's lower atmosphere and warming effect on the lower stratosphere. Comprehensive overview of the impact of volcanic aerosols on climate can be found in Robock (2000, 2015). It is well reported that these volcanic eruptions can release and inject tremendous amount of sulfur dioxide (SO2) directly into the stratosphere. These sulfate aerosols significantly reflect the solar radiation and absorb the infrared radiation, causing cooling of the troposphere and heating of the stratosphere. The major volcanic eruptions, such as 'El Chichon' in 1982 and 'Pinatubo' in 1991, emitted large amounts of SO2, and their impacts on global climate have been discussed in several studies (e.g., Aquila et al., 2013; Free and Lanzante, 2009; Randel et al., 2009). It is reported that the Pinatubo eruption in 1991, caused a global tropospheric warming of up to $0.6 \mathrm{~K}$ and a stratospheric warming of 2 K for up to the first two post-eruption years (Parker et al., 1996; Robock, 2000; Ramaswamy et al., 2001).

It is well demonstrated that the atmospheric temperatures are strongly influenced by volcanic plumes. In recent decade, few studies have reported on the impact of 
55 volcanic eruptions on changes in the temperature structure by using high vertical 56 resolution measurements from Global Position System (GPS) radio occultation (RO)

57 technique, relying on the high-precision measurements of atmospheric temperature by the RO technique (Wang et al., 2009; Okazaki and Heki, 2012). For the first time, Wang et al. (2009) and Okazaki and Heki (2012) utilized Constellation Observing System for Meteorology, Ionosphere, and Climate (COSMIC) RO temperature data to study the impact of volcanic eruptions on atmospheric temperature comparing $\mathrm{RO}$ temperature data before and after the eruption. However, the reports are made by using a very less number of RO data. Mehta et al. (2015) studied the impact of recent minor volcanic eruptions on the upper troposphere and lower stratosphere (UTLS) temperature from COSMIC RO data. Biondi et al. (2017) extensively used COSMIC RO data to detect the volcanic cloud top altitude from the bending angle anomaly. Very recently, Stocker et al. (2019) clearly demonstrated the importance of the small volcanic eruptions to the short term temperature trends and they found that the impact of those volcanic eruptions on linear trends can be up to $20 \%$, depending on altitude and latitude. It is also reported that the accurate quantification of temperature changes due to the small eruptions is challenging (Stocker et al., 2019). Indeed, the detailed knowledge of the changes in the vertical temperature structure due to the volcanic eruption is crucial for estimating the accurate trends in the temperature as the impact of volcanic eruptions are altitude and latitude dependent (Stocker et al., 2019).

Recently, on 12 January 2020, a large scale eruption started over the Taal volcano in the Philippines $\left(14^{\circ} \mathrm{N} 120^{\circ} .59 \mathrm{E}\right)$ for the first time since 1977 . At 2.30 p.m. (local time), explosive eruption started and produced a giant plume of volcanic ash up to $\sim 15$ $\mathrm{km}$ in the atmosphere (Mallapaty et al., 2020). This volcanic ash further spread in the northeast direction from the Taal volcano and covered the tropical Pacific Ocean in the northern hemisphere (https://so2.gsfc.nasa.gov/omps_2012_now.html\#2020). Based 
81 on Philippine Institute of Volcanology and Seismology Taal volcano bulletin reports,

82 the Taal volcanic eruption was active during 12-15 January. From 16 January onwards,

83 it has been characterized by week plume activity over the Taal main crater. In the

84 present study, we use COSMIC-2 mission RO temperature data for the first time to

85 investigate the atmospheric temperature changes due to the Taal volcanic eruption 86 during January 2020.

87

88

89

90

91

92

93

94

95

96

97

\section{Data Base}

\subsection{COSMIC-2 provisional data}

In the present study, high-resolution temperature profiles obtained from the COSMIC-2 mission are utilized during January 2020. The COSMIC-2 mission, launched on 25 June 2019, collects more than 5000 RO soundings per day over the tropics and subtropics (Ho et al., 2019). The basic advantage of the COSMIC-2 mission is in that it will take frequent measurements over the tropics and provide higher numbers of temperature profiles in a single day compared to the previous missions due to its low inclination of $\sim 24^{\circ}$. The data is downloaded from the COSMIC Data Analysis and Archive Centre (CDAAC) website (https://data.cosmic.ucar.edu/gnssro/cosmic2/provisional/release1/level2/). In the present study, we used wetprf temperature profiles with $100 \mathrm{~m}$ vertical resolution. Figure $\mathbf{1}$ shows the daily total available COSMIC-2 RO profiles within the study region between 0-35N, 110-180E. We have found a sufficient number of RO profiles over the study region with more than 200 profiles per day. The available RO profiles per day are much higher compared to the other previous RO missions, including COSMIC-1. The COSMIC-2 mission will give a higher density of the temperature profiles over the tropics. Hence, it is plausible to study the diurnal variability of temperature and tropospheric humidity changes over the tropics. 
107

108

109

110

\section{1}

112

113

114

115

116

117
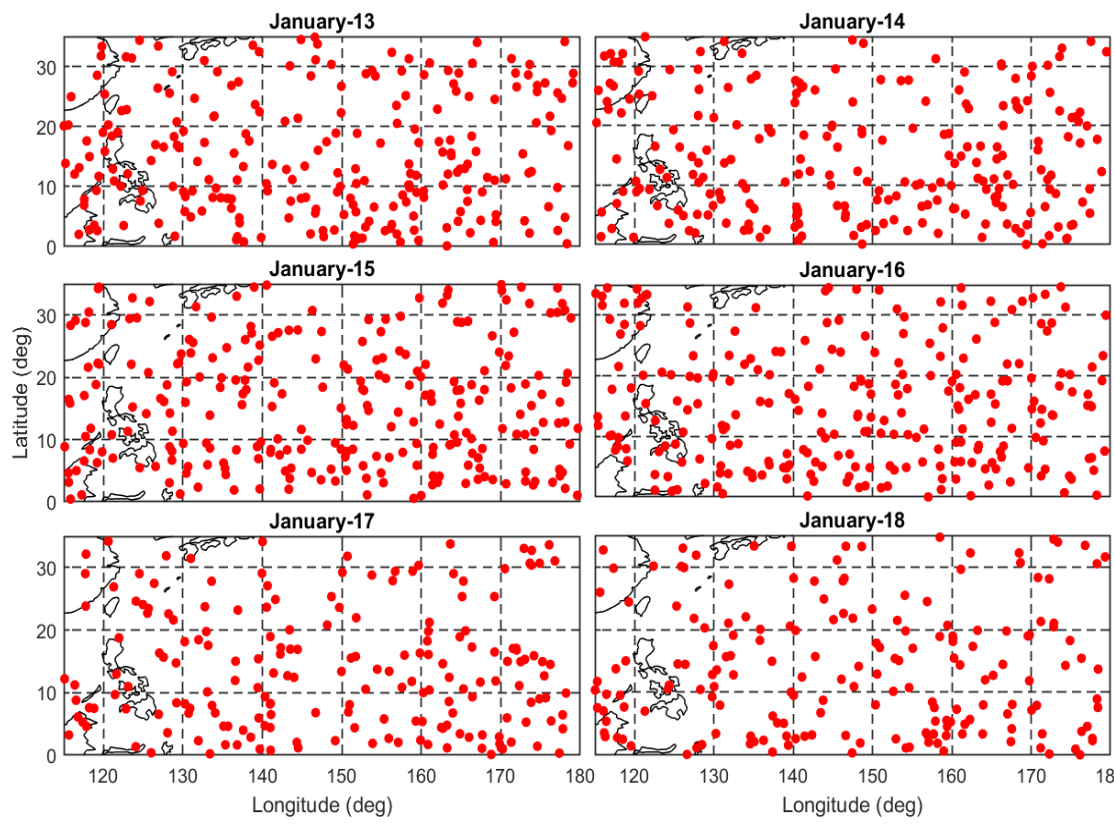

January-16

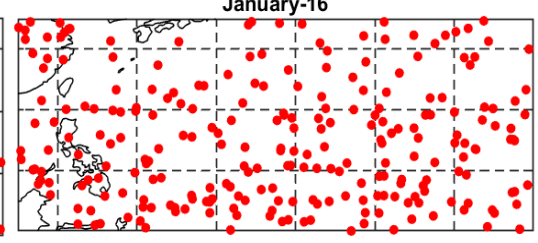

January-18

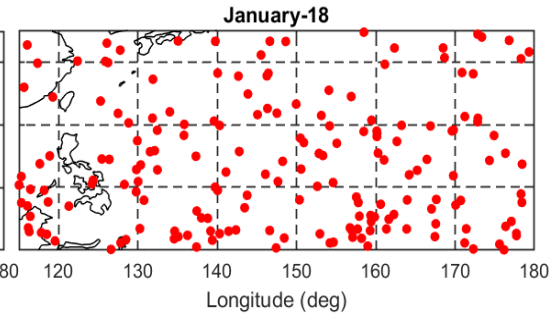

Figure 1. Spatial distribution of COSMIC-2 radio occultation profiles observed during 13-18 January 2020 over 0-35N, 110-180E region.

\subsection{Ozone Monitoring Instrument (OMI) SO2 data}

To geographically identify the area covered by volcanic plume, we used the operational product estimate of the column density of $\mathrm{SO}_{2}$ for the middle tropospheric column (ColumnAmountSO2_TRM) data from the Aura Ozone Monitoring Instrument (OMI). The Aura OMI retrieves the $\mathrm{SO}_{2}$ data from Earthshine radiance in the wavelength range of $310.5-340 \mathrm{~nm}$ (Levelt et al., 2006). It gives the total number of $\mathrm{SO}_{2}$ molecules in the entire atmospheric column above a unit area (https://disc.gsfc.nasa.gov/datasets/OMSO2e V003/). Details of the retrieval technique are documented by $\mathrm{Li}$ et al. (2017). The standard deviation of TRM retrievals in background areas is about $0.3 \mathrm{DU}$ at low and mid-latitudes. The middle tropospheric $\mathrm{SO} 2$ column is corresponding to the center of mass altitude (CMA) of $8 \mathrm{~km}$, generally recommended for use in studies on moderate eruptions and long-range transport of 

data during the Taal volcanic eruption. The NCEP wind data were downloaded from

website

127 https://psl.noaa.gov/data/gridded/data.ncep.reanalysis.pressure.html.

\section{Results and Discussions}

130

Figure 2 shows the evolution of the OMI observed middle tropospheric SO2 column between 13 and 18 January 2020 along with NCEP reanalysis background winds at $150 \mathrm{hPa}$. Here, we plotted SO2 data for all the available OMI satellite granules in each day within the study region during 13 - 18 January 2020. One can notice that there exist large data gaps over the study region during the Taal volcanic eruption. However, we can find significant SO2 signals from the OMI observations. It is reported that the plume of volcanic ash reached up to $\sim 15 \mathrm{~km}$ during Taal volcanic eruption (Mallapaty et al., 2020). From Figure 2, it is evident that immediately after the eruption in the afternoon on 12-13 January, the entire plume at the upper level in the atmosphere moved towards the northeast from the source region due to the strong background winds. Then, it was entrained by the strong anticyclonic circulation over the western Pacific region in the northern hemisphere. Finally, the $\mathrm{SO}_{2}$ plume was accumulated within the anticyclone and moved along with the background winds. A clear anticyclonic flow over the western Pacific was evident from the $150 \mathrm{hPa}$ winds (Figure 2). On 13 January, this anticyclonic center was centered between $10-20 \mathrm{~N}, 150-160 \mathrm{E}$ region. This anticyclone was further moved towards the central Pacific region by the end of 18 

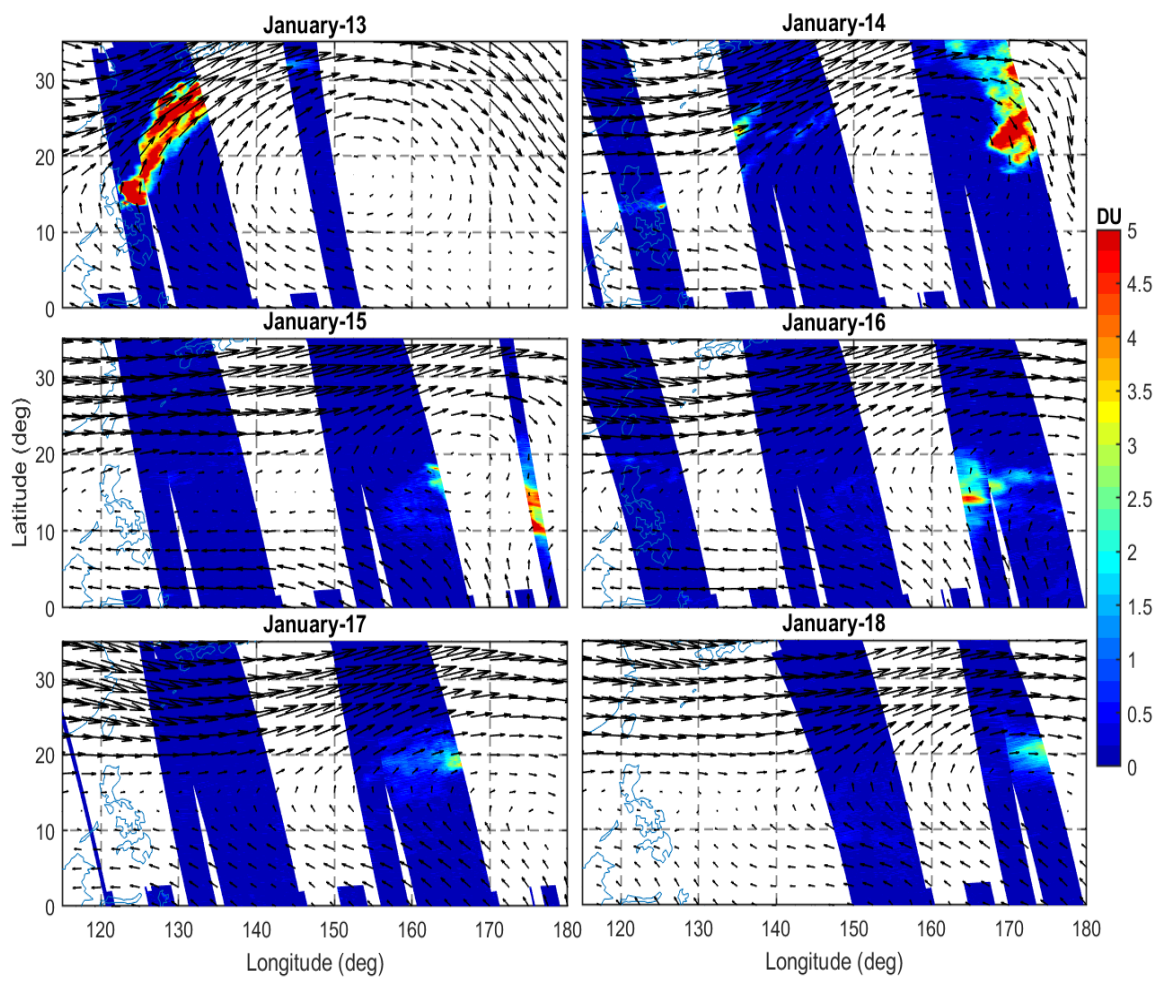

Figure 2. Spatial distribution of middle tropospheric column (TRM) sulfur dioxide $\left(\mathrm{SO}_{2}\right)$ from Aura ozone monitoring instrument (OMI) for each day, 13-18 January 2020. (Unit: Dobson units; 1DU $=2.69 \times 10^{16}$ molecules $\mathrm{cm}^{-2}$ ).

However, during the time period of 15 -18 January, the center of the anticyclone was strongly located over the region of $10-20 \mathrm{~N}, 160-180 \mathrm{E}$. The $\mathrm{SO}_{2}$ observations from the OMI clearly exhibited a significant signal of the $\mathrm{SO}_{2}$ within the anticyclone during 15-18 January (Figure 2). We also observed significant $\mathrm{SO}_{2}$ signal during 19 and 20 January over this region with less magnitude (Figure not shown). Overall, the $\mathrm{SO}_{2}$

157 released from the Taal volcanic eruption in the afternoon on 12-13 January, transported through the upper level strong winds and into a strong anticyclone over the Pacific

159 Ocean in northern hemisphere. This is quite interesting that the strong anticyclonic circulation at upper level plays a crucial role in transporting the $\mathrm{SO}_{2}$ from the Taal volcanic eruption. In the following sections, the impact of this Taal injected $\mathrm{SO}_{2}$ on the 
temperature structure is discussed in detail.

\subsection{Temperature structure during Taal volcanic eruption}

It is clear that the Taal volcanic eruption started in the afternoon of 12 January and active throughout 13 January. The intensity of the eruption gradually decreased from 14 January and the eruption had dried up by the end of 15 January. Even significant eruption signals with less magnitude are detected over the Taal volcano after 15 January, the maximum $\mathrm{SO}_{2}$ emission was recorded high on 13 January with measured value of $\sim 5299$ tones/day based on Philippine Institute of Volcanology and Seismology. It is

13 January as an intense volcanic eruption day.
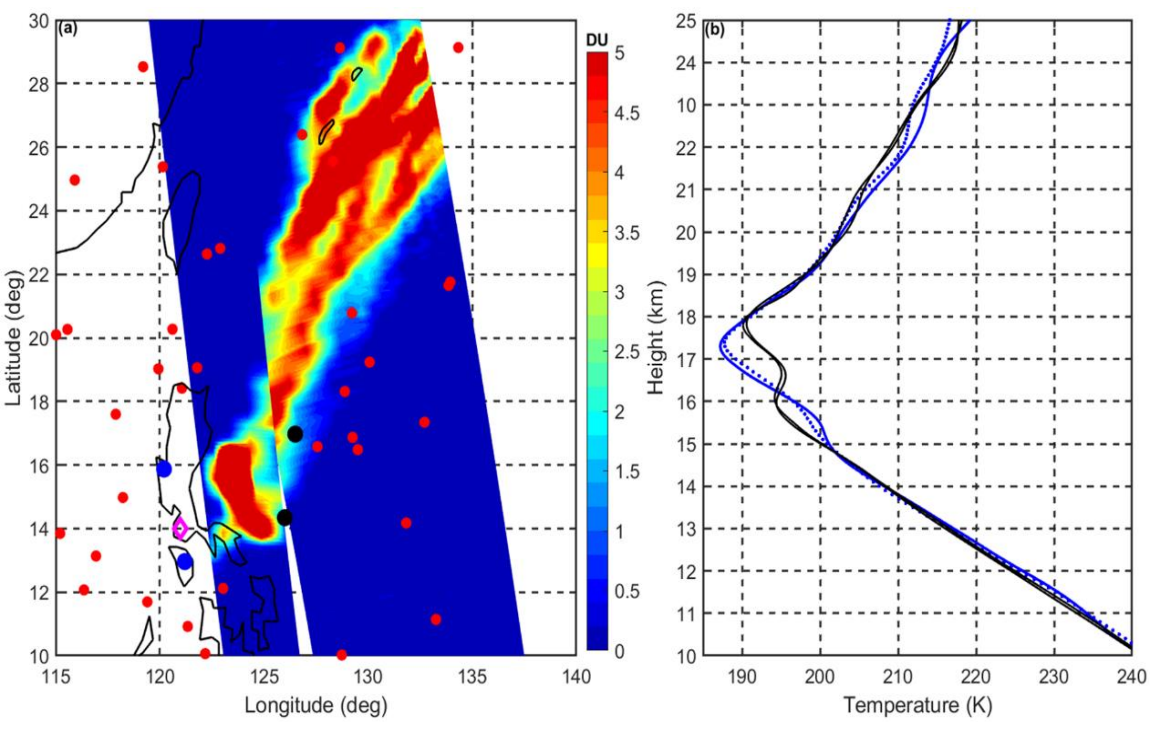

Figure 3. (a) Spatial distribution of COSMIC-2 RO profiles on 13 January around the area of Taal volcano. Magenta colored rectangle represents the location of the Taal volcano. Blue colored dots represent the nearest RO profiles to the volcano, and black dots represent the profiles away from the volcano; and (b) the corresponding temperature profiles for nearest and away regions from the volcano. 
180 Figure 3 shows the available RO data around the Taal volcano on 13 January along

181 with the OMI observed $\mathrm{SO}_{2}$ data on the same day. The area of the Taal volcano is shown

182 by the magenta colored rectangle in the figure. On January 13, we found two

183 temperature profiles from COSMIC-2 RO data in the area of the eruption (within 200

$184 \mathrm{~km}$ from the eruption center), highlighted in blue colored dots in the figure. Two more temperature profiles are also detected away from the eruption center, significantly

186 affected by the volcanic plume (highlighted with black colored dots). The observed

187 vertical temperature profiles for near source region and away from the source region are shown in Figure 3b.

It is very interesting that the vertical temperature structure is quite different from around the center to away from the volcanic eruption. Between 10 and $15 \mathrm{~km}$, the temperature profiles exhibit similar structure, whereas above $15 \mathrm{~km}$ the temperature profiles show different structure. Near the center of the eruption, the temperature inversion was observed around $15 \mathrm{~km}$ and the cold point tropopause height is noticed around $17 \mathrm{~km}$ altitude (blue colored profiles). However, away from the volcano, the inversion started at $16 \mathrm{~km}$ altitude and the cold point tropopause height is detected around $18 \mathrm{~km}$. Also, $\sim 5 \mathrm{~K}$ difference is observed between the temperature profiles near and away from the volcano at the tropopause during the active eruption period. This is quite interesting and strongly evident that the multiple tropopauses are noticed in the temperature profiles that are available away from the volcano center. longitude radius from the volcano center. In total, there are 14 temperature profiles within the $\pm 5^{\circ}$ latitude and longitude around the volcano center on January 13 as shown in Figure 4a. The corresponding observed vertical temperatures are shown in Figure

204 4a. From the Figure 4a, it is again evident that the temperature structure is quite different from one to the others, particularly between 15 to $20 \mathrm{~km}$ altitude ranges. We 
206 also detected the multiple tropopauses in most of the temperature profiles. To quantify

207 the temperature changes in the active volcanic eruption day, we compared the

208 temperature profiles available on 13 January with the mean temperature of a week

before the eruption (here after background mean temperature). The background mean

210 temperature is computed using all the temperature profiles during 5-11 January that are available within $\pm 5^{\circ}$ latitude and longitude radius from the volcano center. Finally, we

212 subtracted all individual temperature profiles available on 13 January with the background mean temperature. The difference in the temperature profiles is shown in

Figure 4b. The solid black colored line represents the mean of all the temperature difference profiles estimated by using the 14 profiles.
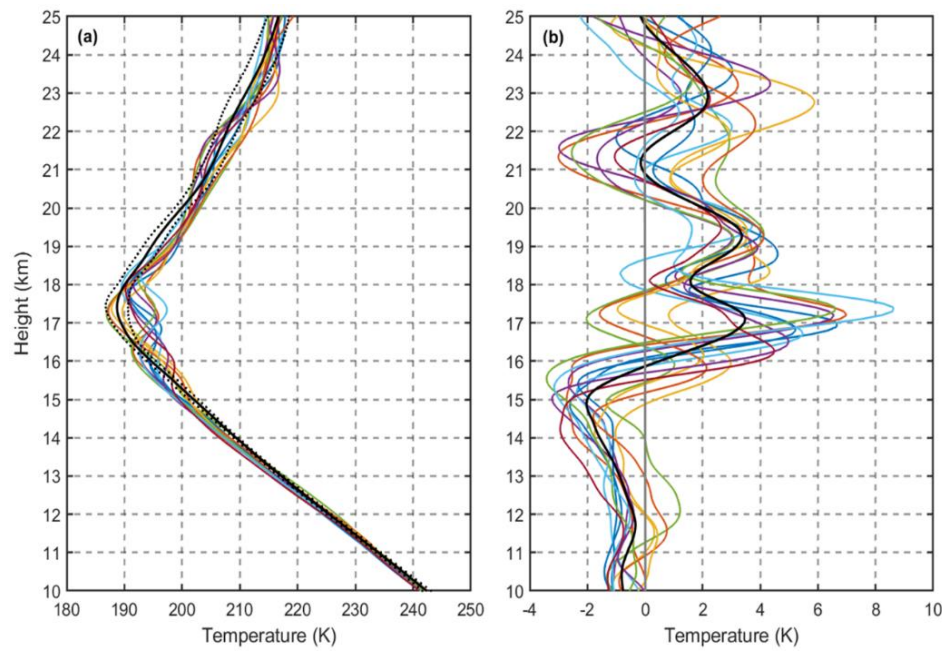

Figure 4. (a) Observed vertical temperature profiles on 13 January along with mean temperature (black) of one week before the eruption within the 5 degree radius from the Taal volcano, and (b) temperature difference of the available temperature profiles within the 5 degree radius for one week before the eruption. Black dotted lines showed in (a) are the standard deviation for the mean temperature of one week before the eruption.

From Figure $\mathbf{4 b}$, it is clear that all the profiles exhibit significant negative temperature anomalies in the $10-15 \mathrm{~km}$ region. The mean of maximum negative temperature anomaly is noticed around $15 \mathrm{~km}$ altitude. The negative to positive changes 
226 happened at around $16 \mathrm{~km}$ altitude. Further, most of the profiles exhibits positive 227 temperature anomalies from $16 \mathrm{~km}$ altitude onwards. The maximum positive 228 temperature anomaly is of about $3.5 \mathrm{~K}$ in the mean profile, and of up to $\sim 8 \mathrm{~K}$ for 229 individual profiles. It is also evident that there are two maxima positive anomaly 230 locations around $17 \mathrm{~km}$ and $19 \mathrm{~km}$. The observed positive temperature anomaly $\sim 3.5 \mathrm{~K}$ 231 in the upper atmosphere is well matched with previous studies (Wang et al., 2009;

232 Biondi et al., 2017). Overall, from Figure 4 we find clear evidence that the temperature 233 structure after the volcanic eruption shows significantly different from those under 234 normal conditions.

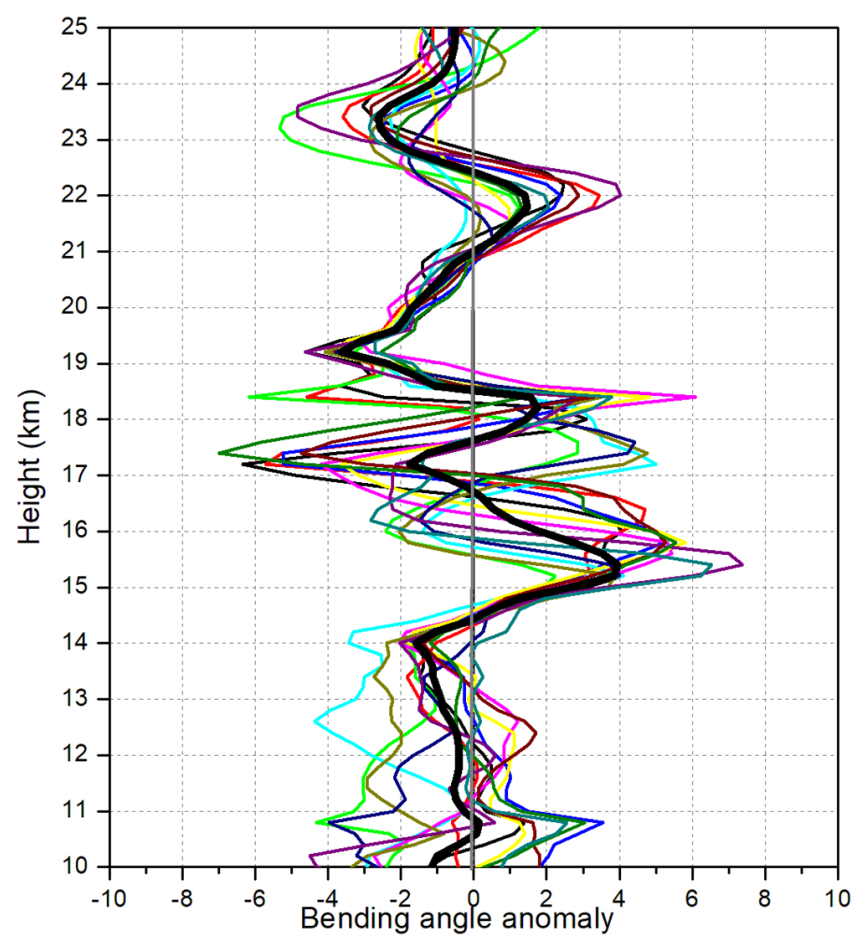

236 Figure 5. Standardized bending angle anomaly observed for the RO profiles available within 5 degree radius from the Taal volcano on 13 January. The anomaly is estimated 238 with reference to the RO profiles available during one week before the eruption over 239 the same region. 
243 method was used to detect the cloud top altitude during the Taal volcanic eruption. The

244 atmprf data from the COSMIC-2 was utilized. Its vertical resolution is $200 \mathrm{~m}$. Figure

2455 shows the standardized bending angle anomaly observed on 13 January 2020 within

246 the degree radius from the volcano. The black colored solid line represents the mean of

247 all 14 profiles. We estimated the bending angle anomaly with reference to the one week

248 before the eruption over the same region. First, we subtracted the reference mean

249 bending angle profile from the individual bending angle profiles around the volcano.

250 The anomalies are further standardized with the reference data. A prominent peak in

251 the bending angle anomaly defines the volcanic clout top altitude. From the mean

252 profile of bending angle anomaly (black colored solid line), the maximum peak is

253 detected at $15.2 \mathrm{~km}$. It is suggesting that the clouds reached the altitude of $15.2 \mathrm{~km}$

254 during the Taal volcanic eruption. This is quite different from the temperature

255 anomalies shown in Figure 4b. The maximum positive temperature anomaly is noticed

256 at $\sim 17 \mathrm{~km}$ which is quite higher than the bending angle. Our study also further supports

257 the detection of the cloud top altitude during the volcanic eruption.

258 We also investigated the tropopause changes due to this eruption. Changes in the 259 different tropopause parameters over $\pm 5^{\circ}$ latitude and longitude around the area of the 260 Tall volcano about 7 days before volcano eruption (5-11 January 2020) and just after the volcano eruption (12-15 January 2020) are investigated. Table 1 shows the different

262 tropopause parameters such as cold point tropopause height (CPT-H) and corresponding temperature (CPT-T), lapse rate tropopause height (LRT-H) and corresponding temperature (LRT-T), and convective tropopause height (COT-H) and 
266 between COT-H and CPT-H, for the Taal volcanic eruption that is observed before and 267 just after the eruption. The COT-H is estimated by using the gradient in the potential 268 temperature profile and the maximum gradient in the profile is identified as the COT269 H (Ravindra Babu et al., 2015).

\begin{tabular}{|c|c|c|}
\hline Tropopause Parameter & Before & After \\
\hline CPT-H & $17.6 \pm 0.5$ & $17.2 \pm 0.4$ \\
\hline CPT-T & $188 \pm 2.1$ & $189 \pm 1.7$ \\
\hline LRT-H & $17.1 \pm 0.4$ & $16.9 \pm 0.5$ \\
\hline LRT-T & $188.4 \pm 2.4$ & $189.3 \pm 2$ \\
\hline COT-H & $12.1 \pm 1.5$ & $13.1 \pm 1.3$ \\
\hline TTL thickness & $5.5 \pm 1.7$ & $4.1 \pm 1.4$ \\
\hline
\end{tabular}

Table 1. Mean tropopause parameters observed for one week before the eruption and after the eruption. We considered 05-11 January period as one week before and 12-15 January as an after the eruption period.

The CPT-H before the eruption around the Taal region is $17.6 \mathrm{~km}$, whereas the LRT-H is $17.1 \mathrm{~km}$ with a standard deviation of 0.5 and $0.4 \mathrm{~km}$, respectively. Just after the eruption, the CPT-H and LRT-H is slightly changed and the values are recorded as $17.2 \pm 0.4 \mathrm{~km}$ and $16.9 \pm 0.5 \mathrm{~km}$. There is a slightly decrease in the tropopause height just after the eruption. Similarly, the temperatures of tropopause (CPT-T and LRT-T) exhibit a significant increase in value by $\sim 1 \mathrm{~K}$. The observed warmer tropopause temperatures are clear evidence for the presence of $\mathrm{SO} 2$ around the tropopause region during the eruption period. Very interestingly the COT-H is increased by $1 \mathrm{~km}$ just after the eruption as compared with that before the eruption period, and this has led to the increase in the TTL thickness by $1.4 \mathrm{~km}$ after the eruption period. The observed strong increase in the COT-H is strongly due to the volcanic plume during the Taal eruption. 
285 It is reported earlier that the plume of volcanic ash reached up to $\sim 15 \mathrm{~km}$ over the Taal

286 volcano region during the eruption (Mallapaty et al., 2020).

287 3.4 Diurnal variability in temperature and relative humidity

The COSMIC-2 provides more than 5000 high vertical resolution temperature profiles within a day over the tropics ( $\mathrm{Hu}$ et al., 2020). This allows us to see the significant diurnal changes in the basic atmospheric parameters, such as temperature and relative humidity $(\mathrm{RH})$. By utilizing this advantage, we investigated diurnal variability in the atmospheric temperature and relative humidity after the eruption in the study. Two regions were selected, within $\pm 5^{\circ}$ latitude and longitude radius from the Taal volcano as one study region and the area between $10-20 \mathrm{~N}, 160-180 \mathrm{E}$ as a second study region. One can notice that first region has been the source region of $\mathrm{SO}_{2}$ just around the volcanic eruption and another one is the away from the source region, but the injected $\mathrm{SO}_{2}$ from the eruption reached and accumulated over the second region during the Taal eruption. In this way it is important to see how the atmosphere is responded after the eruption over the two different regions. We carried out similar analysis, which is mentioned in the previous sections. We subtracted the daily mean temperatures during 12-31 January from the background temperature over the respective regions. The observed temperature difference between the daily mean temperature and background mean temperature over two regions are shown in Figure behavior over the two regions. The anomaly shown in Figure 6a indicates that a persistent positive temperature anomaly is observed at $16-19 \mathrm{~km}$ altitude region in the area around the Taal volcano and it is remained for several days after the eruption. Whereas, over the Pacific region, the positive temperature anomaly is persisting up to 19 January, after that there was a noticeable drop in the positive temperature anomaly 
next few days.
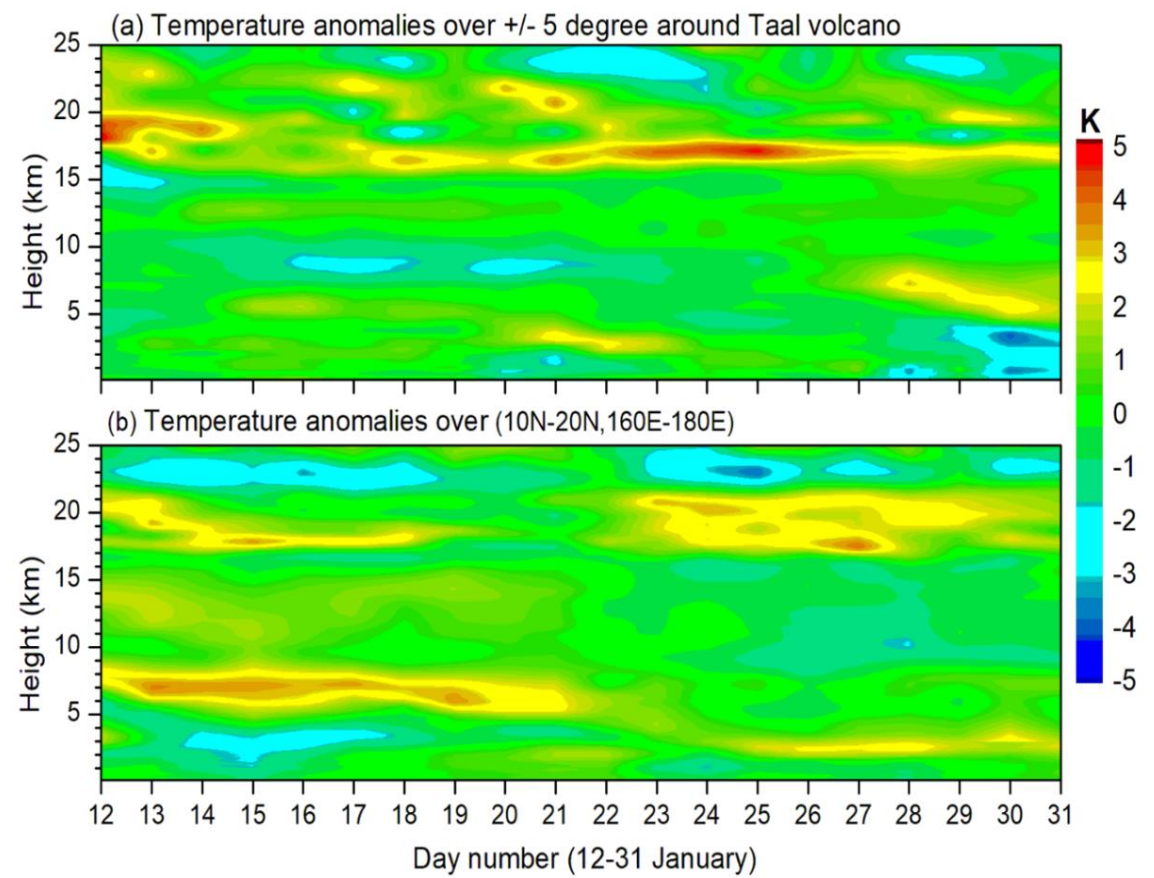

Day number (12-31 January)

313 Figure 6. Observed daily mean temperature anomalies over (a) \pm 5 degree around the

314 Taal volcano, and (b) region around 10-20N, 160-180E.

315 The maximum warming over the Tall volcano region is observed at $18 \mathrm{~km}$ altitude

316 on 13 January with the magnitude of $\sim 4 \mathrm{~K}$ (Figure 6a). The temperature anomalies at

$317 \quad 17-19 \mathrm{~km}$ altitude range during 12-15 January significantly exhibit warmer compared to the remaining days (Figure 6a). We also noticed a significant negative temperature

319 anomaly by about $2-3 \mathrm{~K}$ at $15 \mathrm{~km}$ altitude just after the eruption over the Taal volcano

320 (Figure 6a). However, this feature does not appear over the Pacific region at the same

321 altitude. This may be due to the sudden increase in the atmospheric water vapor at that

322 altitude region. It is expected that large amount of water vapor is transported during the

323 eruption period along with $\mathrm{SO}_{2}$. Over the Pacific region, a significant cooling of the

324 lower stratosphere $(22-25 \mathrm{~km})$ is evident after the eruption. One interesting finding from

325 the Figure $\mathbf{6 b}$ is that there is a layer of warming in the atmosphere around 5-20 km 
326 altitude region. The significant warming in the troposphere might be due to the strong

327 anticyclonic circulation associated with $\mathrm{SO}_{2}$ from the eruption over the region during

328 the eruption period. We also observed significant cooling of the mid troposphere over

329 the Taal volcano region after the eruption (Figure 6a). Overall a warm anomaly of

330 nearly $5 \mathrm{~K}$ at $\sim 18 \mathrm{~km}$ just above the tropopause appears as the eruption signature over

331 the Taal volcano. The persistent warming around the tropopause region appears after

332 the eruption indicating the effect of $\mathrm{SO}_{2}$ plume and its direct radiative effect induces a

333 heating of the atmosphere around the tropopause. Overall, both locations show

334 significant warming of the tropopause region, suggesting that both locations are

335 influenced by the volcanic plume.

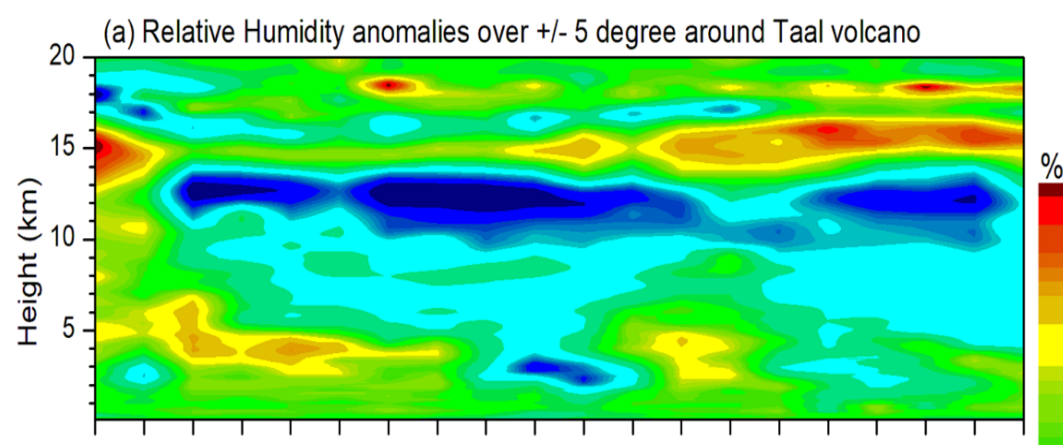

(b) Relative Humidity anomalies over 10N-20N,160E-180E.

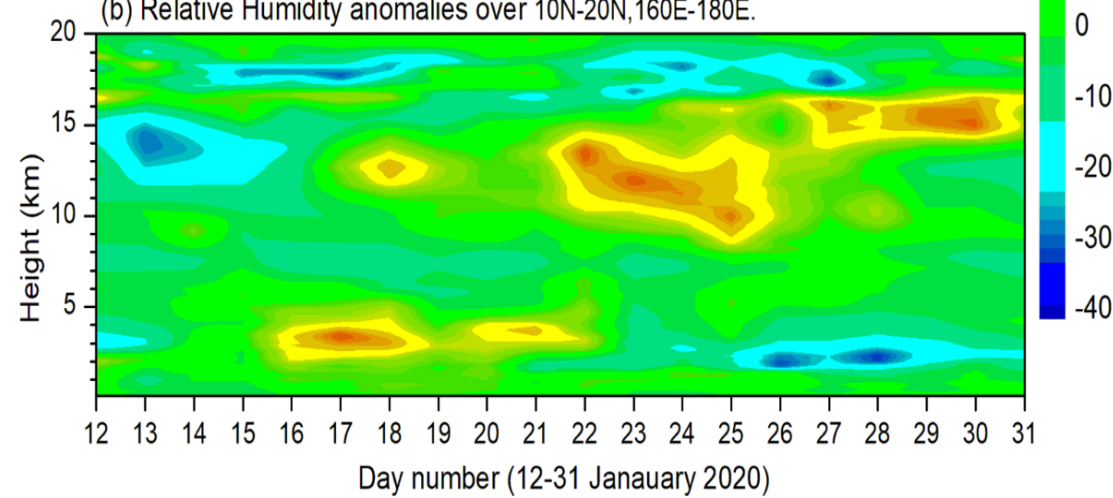

337 Figure 7. Observed daily mean relative humidity anomalies over (a) \pm 5 degrees around

338 the Taal volcano and (b) region around 10-20 N, 160-180 E. 
339 Similarly, the diurnal variability in the RH is also investigated by using the 340 COMSIC-2 RO data and the observed anomalies are shown in Figure 7. Interestingly,

341 the anomalies observed in the RH over two regions exhibit quite different from one to another. A significant increase in the $\mathrm{RH}$ is evident in the mid and upper troposphere with the maximum increase noticed at $\sim 15 \mathrm{~km}$ altitude on just after the eruption over the Taal volcano region. While, in Pacific region, the RH shows a significant decrease after the eruption at $\sim 15 \mathrm{~km}$ altitude range (Figure $7 \mathbf{b}$ ), we also observed a noticeable decrease in the $\mathrm{RH}$ at $\sim 17-19 \mathrm{~km}$ altitude over the Taal volcano region just after the eruption (Figure 7a). Drying of the lower stratosphere due to the presence of $\mathrm{SO}_{2}$ is one of the prominent signatures of the volcanic eruption (Glazeet al., 1997). The observed negative RH anomalies at 17-19 km altitude over the Taal volcano region and at $15 \mathrm{~km}$ altitude over the Pacific region from the present study strongly support the evidence of the eruption signatures. Both locations show significant negative RH anomalies in the lower stratosphere after the eruption, suggesting that both locations

353 are influenced by the volcanic plume. After the eruption, the RH anomalies show 354 persistent decrease in the $\mathrm{RH}$ around the upper troposphere over the Taal volcano region.

355 This is expected that the $\mathrm{SO}_{2}$ emitted from the volcano reacts with water vapor to 356 produce sulphate aerosols over a period of some weeks (Pinto et al., 1989). The observed mid tropospheric negative temperature anomalies from Figure 6a after the eruption over the Taal volcano region are mirrored in the troposphere drying, which is noticed by the large lowering of the RH (Figure 7a). The RH is lowered by $50 \%$ after the eruption from 14 January onwards over the Taal volcano region. Our results from the $\mathrm{RH}$ observations from COSMIC-2 clearly show the volcano eruption signatures at day-to-day time scales. It is reported that the impact of small volcanic eruptions on the temperature changes is varied with respect to altitude and latitude (Stocker et al., 2019). 


\section{Conclusion}

Very recently, on the afternoon of 12 January 2020, a large eruption occurred at the Taal volcano located in the Philippines $\left(14^{\circ} \mathrm{N} 120.59^{\circ} \mathrm{E}\right)$. This was the first time since its previous eruption in 1977. However, this eruption during January 2020 was active for a few days and it was weakened just after a few days. Though it injected a significant amount of $\mathrm{SO}_{2}$ into the atmosphere and within a few days the injected $\mathrm{SO}_{2}$ transported towards the central Pacific Ocean in the northern hemisphere due to the

375 strong upper level winds. The injected $\mathrm{SO}_{2}$ reached at about $\sim 15 \mathrm{~km}$ during its active eruption period. In the present study, we have analyzed the temperature structure and

377 its variability during and after the eruption. We used high resolution temperature measurements from recently launched COSMIC-2 mission for the first time. As

379 COSMIC-2 provides a much higher number of temperature profiles compared to the previous RO missions over the tropics in a single day, we examined the temperature and also relative humidity changes due to the eruption at day-to-day scales. Previously, few studies reported the temperature changes after the volcanic eruption by using a small number of RO data (Wang et al., 2009; Okazaki and Heki, 2012). Wang et al. (2009) and Okazaki and Heki, (2012) studied the eruptions occurred over the mid latitude regions. However, they reported the instantaneous and localized temperature changes associated with the eruptions. Biondi et al. (2017) firstly studied the volcanic eruption over the tropics by using COSMIC RO data. They studied the Nabro eruption,

388 which occurred in June 2011 over the tropics. They reported the positive temperature anomaly by about $4 \mathrm{~K}$ in the mean, and up to $10 \mathrm{~K}$ for the individual profile in the UTLS 
region. They considered $10^{\circ} \times 10^{\circ}$ latitude and longitude area around the Nabro volcano.

391 In the present study, we considered the $5^{\circ} \times 5^{\circ}$ latitude and longitude area around the Tall volcano. Our findings of temperature anomaly by about $3.5 \mathrm{~K}$ in the mean profile, and up to $\sim 8 \mathrm{~K}$ for the individual profile are in good agreement with the results of Biondi et al. (2017).

In the present study, we also describe the detailed temperature structure with respect to the distance from the volcano center during its active eruption day. Further, the day-to-day temperature and relative humidity changes over $\pm 5^{\circ}$ latitude and longitude radius from the volcanic center and over the affected region away from the volcano (10-20 N, 160-180 E). We compared the temperature and $\mathrm{RH}$ with respect to the mean data of one week before the eruption when there was no volcanic eruption. The present results in day-to-day temperature and RH changes immediately after the eruption are the first of its kind of very shorter scales, which are not presented earlier. We found a clear warming signature in the lower stratosphere region due to the $\mathrm{SO}_{2}$ after the eruption of Taal with mean amplitudes about $5 \mathrm{~K}$ just after the eruption and persisting for the next two weeks. Overall, significant increased RH in the troposphere and lowering of the $\mathrm{RH}$ in the lower stratosphere along with the warming of the tropopause region due to the presence of $\mathrm{SO}_{2}$ are the strong signatures of the Taal volcanic eruption. The major findings from the present study are summarized as follows

- A significant temperature inversion at $\sim 15 \mathrm{~km}$ altitude is observed in the nearest temperature profiles (within 2-degree radius). Multiple tropopauses are evident in the temperature profiles that are available away from the volcano $(\sim 5$-degree radius).

- $\mathrm{A} \sim 3.5 \mathrm{~K}$ in the mean profile and up to $\sim 8 \mathrm{~K}$ warming for individual profile was observed within $\pm 5^{\circ}$ latitude and longitude from the volcano center compared to one week before the eruption when there was no volcanic eruption on 13 January. 
416

417

418

419

420

421

422

423

424

425

426
- A persistent warming layer at $16-19 \mathrm{~km}$ altitude region is evident over the Taal volcano region (Pacific region) and it is further remained for several days after the eruption.

- A significant increase (decrease) in the RH is evident in the mid and upper troposphere with the maximum increase is noticed at $\sim 15 \mathrm{~km}$ altitude on just after the eruption over the Taal volcano region (Pacific region).

- The present work shows the advantages and the usefulness of the COSMIC-2 data for near real-time temperature monitoring at shorter time scales with higher density of the data.

In recent period, the small volcanic eruption research has got immense interest in the scientific community. Hence, several studies were reported on the impact of the small volcanic eruptions on the atmospheric temperature (Wang et al., 2009; Okazaki and Heki, 2012; Mehta et al., 2015; Stocker et al., 2019). Also, a contribution of those eruptions to the 21 st century warming hiatus has been discussed earlier (Santer et al., 2015). To represent the comprehensive trends in the atmospheric temperatures, the detailed knowledge and understanding of the vertical temperature structure is crucial particularly during volcanic eruptions. The recently launched COSMIC-2 RO data provide higher density of the finer temperature profiles over the tropics in a single day. From the present study, it is concluded that the COMSIC-2 data is also suitable for study the small scale variability in the atmospheric temperature and relative humidity during different extreme events (volcanic eruptions, tropical cyclones etc.) particularly over the tropics.

Author contributions: S. Ravindra Babu designed the study, conducted research, performed complete data analysis and drafted the first manuscript. Y.-A. Liou edited the first manuscript. S. Ravindra Babu and Y.-A. Liou finalized the manuscript for communication with the journal. 
442 Competing interests: The authors declare that they have no conflict of interest.

443

444 Acknowledgments: We thank the COSMIC Data Analysis and Archive Centre

445 (CDAAC) for providing COSMIC-2 provisional data used in the present study through 446 its FTP site (http://cdaac-www.cosmic.ucar.edu/cdaac/products.html). We also thank 447 NASA for providing the Aura Ozone Monitoring Instrument (OMI) data 448 (https://disc.gsfc.nasa.gov/datasets/OMSO2e_V003/). Thanks to NCEP for providing 449 the wind data. Appreciations are also due to the Ministry of Science and Technology 450 (MOST) of Taiwan for financial support through grants MOST 108-2111-M-008-036451 MY2 and 108-2923-M-008-002-MY3.

452

\section{Data Availability}

453 All the data used in the present study is available freely from the respective websites. 454 The COSMIC RO data is available from COSMIC CDAAC website (http://cdaac455 www.cosmic.ucar.edu/cdaac/products.html). The NCEP wind data available from 456 https://psl.noaa.gov/data/gridded/data.ncep.reanalysis.pressure.html. The Aura OMI $\begin{array}{lllll}\mathrm{SO}_{2} & \text { data } & \text { is } & \text { freely } & \text { available }\end{array}$

458 https://disc.gsfc.nasa.gov/datasets/OMSO2e_V003/.

\section{References}

460
Aquila, V., Oman, L. D., Stolarski, R., Douglass, A. R., and Newman, P. A.: The Response of Ozone and Nitrogen Dioxide to the Eruption of Mt. Pinatubo at Southern and Northern Midlatitudes, J. Atmos. Sci., 70, 894-900, https://doi.org/10.1175/JAS-D-12-0143.1, 2013.

Biondi, R., Steiner, A. K., Kirchengast, G., Brenot, H., and Rieckh, T.: Supporting the detection and monitoring of volcanic clouds: A promising new application of Global Navigation Satellite System radio occultation, Adv. Sp. Res., 60, 2707- 

Radio Occultation Advances the Monitoring of Volcanic Clouds: The Case of the 2008 Kasatochi Eruption, Remote Sens. 2019, 11, 2199, https://doi.org/10.3390/rs11192199

472 Free, M. and Lanzante, J.: Effect of volcanic eruptions on the vertical temperature 473 profile in radiosonde data and climate models, J. Clim., 22, 2925-2939, 474 https://doi.org/10.1175/2008JCLI2562.1, 2009.

475 Glaze, L. S., Baloga, S. M., and Wilson, L.: Transport of atmo-spheric water vapor by 476 volcanic eruption columns, J. Geophys.Res., 102, 6099-6108, 1997.

477

Ho et al. (2019) The COSMIC/FORMOSAT-3 radio occultation mission after 12 years: Accomplishments, remaining challenges, and potential impacts of COSMIC-2. Bull Amer Met Soc 100 online version: https://journals.ametsoc.org/doi/pdf/10.1175/BAMS-D-18-0290.1

Levelt, P. F., Oord, G. H. J. v. d., Dobber, M. R., Malkki, A., Huib, V., Johan de, V., Stammes, P., Lundell, J. O. V., and Saari, H.: The ozone monitoring instrument, IEEE T. Geosci. Remote Sens., 44, 1093-1101, https://doi.org/10.1109/TGRS.2006.872333, 2006.

Li, C., Krotkov, N. A., Carn, S., Zhang, Y., Spurr, R. J. D., andJoiner, J.: Newgeneration NASA Aura Ozone Monitoring In-strument (OMI) volcanic SO2dataset: algorithm description, ini-tial results, and continuation with the Suomi-NPP Ozone Map-ping and Profiler Suite (OMPS), Atmos. Meas. Tech., 10, 445-458, doi:10.5194/amt-10-445-2017, 2017.

Mallapaty, S.: Scientists fear major volcanic eruption in the Philippines, Nature, 2020. 
491

492

493

Mehta, S. K., Fujiwara, M., Tsuda, T., \& Vernier, J. P. (2015). Effect of recent minor volcanic eruptions on temperatures in the upper troposphere and lower stratosphere. Journal of Atmospheric and Solar-Terrestrial Physics, 129, 99-110. https://doi.org/10.1016/j.jastp.2015.04.009

Okazaki, I. and Heki, K.: Atmospheric temperature changes by vol-canic eruptions: GPS radio occultation observations in the 2010Icelandic and 2011 Chilean cases, J. Volcanol. Geoth. Res., 245-246, 123-127, 2012.

Parker, D. E., Wilson, H., Jones, P. D., Christy, J., and Folland, C.K.: The impact of Mount Pinatubo on climate, Int. J. Climatol.,16, 487-497, . https://doi.org/10.1002/(SICI)1097-0088, 1996.

Pinto, J. P., Turco, R. P., and Toon, O. B.: Self-limiting physical andchemical effects in volcanic eruption clouds, J. Geophys. Res., 94, 1116511174,doi:10.1029/JD094iD08p11165, 1989.

Ramaswamy, V., Chanin, M. L., Angell, J., Barnett, J., Gaffen, D., Gelman, M., Keckhut, P., Koshelkov, Y., Labitzke, K., Lin, J. J. R., O'Neill, A., Nash, J., Randel, W., Rood, R., Shine, K., Shiotani, M., and Swinbank, R.: Stratospheric temperature trends: Observations and model simulations, Rev. Geophys., 39, 71122, https://doi.org/10.1029/1999rg000065, 2001.

Randel, W. J., Garcia, R. R., Calvo, N., and Marsh, D.: ENSO influence on zonal mean temperature and ozone in the tropical lower stratosphere, Geophys. Res. Lett., 36, 1-5, https://doi.org/10.1029/2009GL039343, 2009.

RavindraBabu, S., VenkataRatnam, M., Basha, G., Krishnamurthy, B.V., and Venkateswararao, B.: Effect of tropical cyclones on tropical tropopause parameters observed using COSMIC GPS RO data. Atmos. Chem. Phys, doi: 10.5194/acp- 
516 Robock, A.: Volcanic eruptions and climate. Reviews of Geophysics, 38(2), 191-219.

$517 \quad$ https://doi.org/10.1029/1998rg000054, 2000.

518 Robock, A.: Climatic impacts of volcanic eruptions Edited by H. Sigurdsson (pp. 935519 942). https://doi.org/10.1016/B978-0-12-385938-9.00053-5, 2015.

520 Santer, B. D., Solomon, S., Bonfils, C., Zelinka, M. D., Painter, J. F., Beltran, F., et al.:

521 Observed multivariable signals of late 20th and early 21 st century volcanic activity.

522 Geophysical Research Letters, 42, 500-509. 523 https://doi.org/10.1002/2014GL062366, 2015.

524 Stocker, M., Ladstädter, F., Wilhelmsen, H., and Steiner, A. K.: Quantifying 525 stratospheric temperature signals and climate imprints from post-2000 volcanic 526 eruptions. Geophysical Research Letters, 46, 12,486-12,494. $527 \quad$ https://doi.org/10.1029/2019GL084396, 2019.

528 Vernier, J.-P., Thomason, L. W., Pommereau, J.-P., Bourassa,A. E., Pelon, J., Garnier, 529 A., Hauchecorne, A., Blanot, L.,Trepte, C., Degenstein, D., and Vargas, F.: Major 530 influence oftropical volcanic eruptions on the stratospheric aerosol layerduring the 531 last decade, Geophys. Res. Lett., 38, 532 L12807,https://doi.org/10.1029/2011GL047563, 2011.

533 Wang, K.Y., Lin, S.C., Lee, L.C.: Immediate impact of the Mt Chaiten eruption on 534 atmosphere from FORMOSAT-3/COSMIC constellation. Geophys. Res. Lett. 36, $535 \quad$ L03808, 2009. 